\title{
Using Soursop Extracts for Natural Gout Treatment
}

\author{
Mufeed Jalil Ewadh" ${ }^{1,}$, Maha Fadhil Smaism", Ali Mohammed Jawad², Samr Mkhlof ${ }^{3}$, \\ Osama Muzahim Aljubouri ${ }^{4}$, Muna Mufeed Ewadh ${ }^{1}$
}

${ }^{1}$ Biochemistry Dept., College of Medicine, University of Babylon, Babylon, Iraq

${ }^{2}$ Ministry of Science and Technology, Baghdad, Iraq

${ }^{3}$ Tishreen University, Faculty of Medicine, Lattakia, Syria

${ }^{4}$ Babylon Health Office, Merjan Taching Hospital, Diabetology Center Medical Laboratory, Babylon, Iraq

\section{Email address:}

mewadh@yahoo.com (M. J. Ewadh)

\section{To cite this article:}

Mufeed Jalil Ewadh, Maha Fadhil Smaism, Ali Mohammed Jawad, Samr Mkhlof, Osama Muzahim Aljubouri, Muna Mufeed Ewadh. Using Soursop Extracts for Natural Gout Treatment. American Journal of Bioscience and Bioengineerin. Vol. 3, No. 5, 2015 , pp. 37-39. doi: $10.11648 /$ j.bio.20150305.12

\begin{abstract}
Soursop extract used to show its effects on the xanthine oxidase activity by inhibition its ability to produce uric acid, the principal reason for the gout and other inflammatory diseases. The fractionation results shows that the major fraction of phenolic compounds is cumarin separated by revise phase high performance chromatography (HPLC) which shows by in vitro test a considerable inhibition of the xanthine oxidase activity equal to $72.15 \pm 0.70$ compared with positive control (Allopurinol) $(\mathrm{P}<0.05)$ which lead to reduce production of uric acid. The atomic absorption analysis $(\mathrm{AA})$ of trace elements (Fe, $\mathrm{Zn}, \mathrm{Mg}, \mathrm{P}$ ) shows the presence of such metals in soursop sample in an amount nessacery for many metabolic processes in human body. In conclusion the cumarin can used as treatment for gout instead of allpurinol because of its side effect. Further histopathological studies need to explore such study to show the effect of cumarin and trace elements on liver and other organs in animal samples.
\end{abstract}

Keywords: Soursop, Gout, Xanthine Oxidase, Trace Elements

\section{Introduction}

Soursop is the fruit of Annona muricata, a broadleaf, flowering, evergreen treenative to Mexico, Cuba, Central America, the Caribbean islands of Hispaniolaand Puerto Rico,and northern South America, primarily Colombia, Brazil, Peru, Ecuador, Venezuela. Soursop is also produced in some parts of Africa, especially in Eastern Nigeria, Southeast Asia and the Pacific. It is in the same genus as the chirimoya and the same family as the pawpaw (papaya).

The soursop is adapted to areas of high humidity and relatively warm winters; temperatures below $5{ }^{\circ} \mathrm{C}\left(41{ }^{\circ} \mathrm{F}\right)$ will cause damage to leaves and small branches, and temperatures below $3{ }^{\circ} \mathrm{C}\left(37^{\circ} \mathrm{F}\right)$ can be fatal. The fruit becomes dry and is no longer good for concentrate.

Soursop is widely promoted (sometimes as "graviola") as an alternative cancer treatment. There is, however, no evidence to show that graviola works as a cure for cancer. In laboratory studies, graviola extracts can kill some types of liver and breast cancer cells that are resistant to particular chemotherapy drugs. But there haven't been any large-scale studies in humans. So we don't know yet whether it can work as a cancer treatment or not [1]
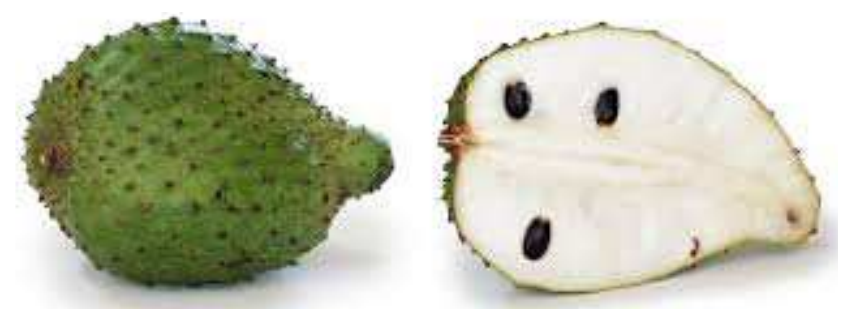

Fig. (1). The fresh Soursop fruit.

Gout is one of the most common metabolic disorders which affects around $13 \%$ of the male population and $5 \%$ of the female population [2] and characterized by an excessive concentration of uric acid in the blood, leading to acute gouty arthritis, tophi of the joints and extremities, and uric acid nephrolithiasis [3]. Elevated levels of uric acid not only leads to gout, but also results in the development of hypertension, cardiovascular disorders, diabetes, obesity, hyperlipidemia and cancer [4]. The therapeutic approach to treat gout is to use either uricosuric agents or xanthine oxidase inhibitors (XOI) in order to block the synthesis of 
uric acid from purines, however to prevent the side effect of drugs there is a need to develop natural compounds with XOI activity. A potential source of such compounds can be obtained from medicinal plants $[5,6]$, such as soursoup.

\section{Materials and Methods}

\subsection{Plant Material and Preparation of the Extract and Fractionation}

The plant material consists of dried powdered prepared as below of the soursoup:

The plant (350 gm without skin) was taken of seeds and slid sheet done and oven dried at $40^{\circ} \mathrm{C}$ for seven days. The dried were ground to fine powder using mill, then finely powdered plant are kept in a dark place at room temperature until the time of use. About $3 \mathrm{~g}$ of the dried powdered was soaked with $50 \mathrm{ml}$ of methanol: water $(7: 3)$ incubated in room temperature for $48 \mathrm{hrs}$. The extract was filtered using What man No.1 filter paper, the solution was evaporated by rotary evaporator at $40{ }^{\circ} \mathrm{C}$. All extract were kept in vacuum desiccators over anhydrous calcium chloride and were kept in the fridge at $4{ }^{\circ} \mathrm{C}$ to be test.

\subsection{Phenolic Compound and Trace Elements Analysis}

\subsubsection{Determination of Total Phenolic Contents}

The total phenolic content in extract were estimated by Folin-Ciocalteau reagent as desicribed by [7]. Then samples allowed for analyzed by High Performance Liquid Chromatography (HPLC) system, model Shimadzu 10AV-LC equipped with binary delivery pump model LC-10AV, the eluted peaks were monitored by UV-VIS10A-SPD spectrophotometer. Standards of suspected compound were run similarly for identification and quantification, concentration of each isolated compound.

The fractions containing low-molecular weight phenolic compounds $(5 \mathrm{ml})$ were collected using a fraction collector and their absorbance was measured at $278 \mathrm{~nm}$. The fractions were eluted from the column with acetonitrile-water (80:20; $\mathrm{v} / \mathrm{v}$ ) [8]. The elutes were then pooled into major fractions. Organic solvents were evaporated at $45^{\circ} \mathrm{C}$ using rotary evaporator.

\subsubsection{Trace Elements Analysis}

The water solution has been allowed for atomic absorption for trace element analysis such as (zinc, iron, manganese, Phosphorus) using Atomic Absorption Spectrophotometer PG990 (9), while the rest of the fractions was lyophilized [10].

\subsection{In Vitro Xanthine Oxidase Inhibitory Activity Assay}

The inhibitory effect on XO was measured following the method reported by [11] using allopurinol $(100 \mu \mathrm{g} / \mathrm{ml})$ as positive control for the inhibition test.

The inhibition percentage of xanthine oxidase activity was calculated according to the formula $=\left(\mathrm{A}_{\text {control }} \mathrm{A}_{\text {sample }}\right) / \mathrm{A}$ control $\times 100 \%[12]$.

\subsection{Statistical Analysis}

Data obtained were expressed as mean \pm standard deviation and the protocol for the statistical analysis applied throughout the experimental part by SPSS version 17 by using $\mathrm{t}$ test. The probability $(\mathrm{P})$ of the measurements was considered to be significant (at $<0.05)$.

\section{Results and Discussion}

\subsection{Total Phenolic Contents in Extract Plant}

Table one shows the total phenolic as mg gallic acid equivalent / $100 \mathrm{mg}$ dry weight of soursop.

Table (1). Total phenolic contents of plants under investigation.

\begin{tabular}{ll}
\hline Extract of plant & Total phenolic (mg gallic acid equivalent/100 g) \\
\hline Soursop & $37 \pm 0.65$ \\
\hline
\end{tabular}

\subsection{Phenolic Compound Analysis}

HPLC analysis showed that fraction of coumarin has the major concentration $(122.8 \mu \mathrm{g} / \mathrm{ml})$ than other compounds. So all following results represent the effect of coumarin on different parameters.

\subsection{In Vitro Xanthine Oxidase Inhibitory (XOI) Activity}

The result shows that the highest XO activity of methanol extract soursop (coumarin fraction) with $70.15 \pm 0.70$ compared with positive control (Allopurinol) $(\mathrm{P}<0.05)$ as show in the table (2). However it is worth to notify that Phytochemical screening of the plant revealed the presence of flavonoids, phenolics, saponins and triterpenoids accounting for its antioxidant properties [13].

Table (2). Xanthine oxidase inhibitory activity of coumarin fraction compered with positive control (Allopurinol).

\begin{tabular}{lll}
\hline Extract of plant & Fraction & \% xanthine oxidase inhibition \\
\hline 1-soursop & coumarin & $70.15 \pm 0.70^{*}$ \\
2-allopurinol & & $67.11 \pm 5.01$ \\
(positive control) & & \\
\hline
\end{tabular}

Result are expressed as mean $\pm \mathrm{SD}(\mathrm{n}=3)$ *indicates $\mathrm{p}<0.05$

Table (3) shows the amount of trace element present in plant juice which which in addition to phenolic compounds gives an indication that why the use of such plant as cancer fighter, however using herbal supplements while undergoing chemotherapy could reduce the efficacy of chemotherapeutic agents due to possible herb-drug interactions [14], but in any way the trace element here could also have catalytic agents for reducing uric acid in patients with gout.

Table (3). Trace elements concentration ( $\mathrm{mg} / 100 \mathrm{gm})$ of sample used in this study.

\begin{tabular}{ll}
\hline Trace element & Concentration in $\mathbf{~ m g} / \mathbf{1 0 0}$ gm of sample \\
\hline $\mathrm{Fe}$ & 0.45 \\
$\mathrm{Zn}$ & 0.08 \\
$\mathrm{Mg}$ & 17 \\
$\mathrm{P}$ & 23 \\
\hline
\end{tabular}




\section{Conclusion}

In conclusion, this study is the first to demonstrate that coumarin fraction of soursop extract possesses significant antioxidant and anti-uricemic activities. Further studies on isolation of some active constituents may lead to the provision of new natural drugs for treatment of hyperuricemia and gout.

\section{Acknowledgment}

The authors would like to extend their appreciation to Mr. Mohammed M. Ewadh for his efforts in typing this manuscript.

\section{References}

[1] http://www.cancerresearchuk.org/about-cancer/cancers-ingeneral/cancer-questions/can-graviola-cure-cancer

[2] Arromede, E., Michet, C. J., Crowson, C. S., O' Fallon, W. M., and Gabriel S.E. Epidemiology of gout: is the incidence rising? J. Rheumatol.; 29, 2403-2406. (2002)

[3] Kramer, HM., and Curhan, G. The association between gout and nephrolithiasis. Am. J. Kid. Dis.; 40, 37-42. (2002)

[4] Lin, K. C, Lin, H. Y, and Chou, P. The interaction between uric acidlevel and other risk factors on the development of gout among asymptomatic hyperuricemic men in a prospective study. J. Rheumatol.; 27, 1501-1505. (2000)

[5] Kong, L. D, Cai, Y., Huang, W. W, Cheng, C. H. K., and Tan, R.X. Inhibition of xanthine oxidase by some Chinese medicinal plants used to treat gout. J. Ethnopharmacol.; 73, 199-207. (2000)

[6] Abdulsamie, H. Altaee., Mufeed J. Ewadh., Haider K. Zaidan
Hormonal contents of two types of Black seed (nigella sativa) oil: comparative study. Medical Journal of Babylon 3 (12), 17-22,(2006)

[7] Ganesh N., Sharma S. K., Dubey S. N., and Sanadya J., Phytochemical screening and estimation of total phenolic content in Aegle marmelos seed. International Journal of pharmaceutical and clinical research; 3 (2):27-29. (2011)

[8] Iswantini, D., N., Darusman, L. K. and T. Inhibition kinetic of Apium graveolen $\mathrm{L}$. ethanol extract and its fraction on the activity of xanthine oxidase and its active compound. (2012)

[9] Rasero, F. S.: Atomic Absorption Spectrophotometric Method for Determination of Water-Soluble Copper in WaterInsoluble Copper Fungicides: CIPAC Collaborative Study. Comparison with Bathocuproine Method. J. Assoc. Off. Anal. Chem., 64: 75-78.( 1981)

[10] Intisar R. A Study of some Natural products as inhibitors of Xanthine Oxidase Activity. M. Sc thesis, Babylon University, College of medicine, Clinical biochemistry Dept. IRAQ (2014)

[11] Umamaheswari, M., Asok Kumar, K., Somasundaram, A., Sivashanmugam, T., Subhadradevi, V. and Ravi, T. K. Xanthine oxidase inhibitory activity of some Indian medicinal plants. Journal of Ethnopharmacology 109 (3): 547-551. (2007).

[12] Bondet, V., Brand-Williams, W., and Berset, C. Kinetic and mechanisms of antioxidant activity using DPPF free radical method. LebensmittelWissenschaft\&technologie.food.Sci.Technol.30, 609-615. (1997)

[13] Costantino, L., Albasini, A., Rastelli, G., and Benvenuti, S. Activity of polyphenolic crude extracts as scavengers of superoxide radicals and inhibitors of xanthine oxidase. Planta. Med.; 58, 342-344.(1992)

[14] Cancer treatment center of America, May 30, (2013). 